Ghanem, M., Hamzeh, F.,Seppänen, O., and Zankoul, E. (2018). "A new perspective of construction logistics and production control: an exploratory study" In: Proc. $26^{\text {th }}$ Annual Conference of the International. Group for Lean Construction (IGLC), González, V.A. (ed.), Chennai, India, pp. 992-1001. DOI: doi.org/10.24928/2018/0540. Available at: www.iglc.net.

\title{
A NEW PERSPECTIVE OF CONSTRUCTION LOGISTICS AND PRODUCTION CONTROL: AN EXPLORATORY STUDY
}

\author{
Malek Ghanem $^{1}$, Farook Hamzeh ${ }^{2}$, Olli Seppänen ${ }^{3}$ and Emile Zankoul ${ }^{4}$
}

\begin{abstract}
Construction logistics and production control can enhance project performance. Research addressing site material management mainlyaims at reducing hauling distances and transportation costs. Other studies address the effects of logistics on labor productivity, proposing partial solutions instead of comprehensive optimization.Moreover, previous research on logistics optimization covers various stages of supply chain, but stops once materials reach the construction site. However, different techniques can be used to haulthese materials from storage areas to workplaces, including push and just-in-time techniques. These methods along with the effects they can have on crew performance still need to be studied. Pull and push techniques have been studied and applied for production control purposes. However, zooming into the level of project locations, the effects of production control approaches on crew performancestill need to be studied. This paper reviews onsite construction logistics and production control techniques, studies them at the level of locations, and proposes hypothesesto be evaluated in future research, relating logistics mechanisms and production control systems to productivity. This research is valuable due to exposing additional factors affecting labor productivity, and recommending further optimization in production planning and construction logistics.
\end{abstract}

\section{KEYWORDS}

Production control, push, pull, logistics, lean construction

1 Masters Candidate, Civil and Environmental Engineering Department, America University of Beirut, Beirut Riad El-Solh 1107 2020, Lebanon, mng08@mail.aub.edu

2 Assistant Professor, Civil and Environmental Engineering Department, American University of Beirut, Beirut Riad El-Solh 1107 2020, Lebanon, fh35@aub.edu.lb

3 Professor of Practice, Department of Civil Engineering, Aalto University, Finland, olli.seppanen@aalto.fi

4 Graduate, Civil and Environmental Engineering Department, American University of Beirut, Beirut Riad El-Solh 1107 2020, Lebanon, efz00@ aub.edu.lb 


\section{INTRODUCTION AND LITERATURE REVIEW}

Construction logistics management may be defined as the management of the process of delivering materials and resources required at a construction site in a productive way. It is not only the management of the flow of material and information, but includes also delivering quality, ensuring safety, and providing an environment that facilitates construction activities (Guffond and Leconte 2000).

Construction logistics is divided into offsite and onsite material logistics. Offsite construction logistics is a part of supply chain management, in which various firms work collaboratively forming a network of inter-related processes to move material, services, funds and information in an effective way that reduces total costs, decreases total lead time, and improves total profits, keeping customer's value above all goals (Hamzeh et al. 2007). In contrast, site material management may be defined as the practice of allocating spaces for resource delivery, storage, and handling in order to reduce site congestion and excess material movement, so that inefficiencies are minimized (Thomas et al. 2005). Site material management affects then the workers' productivity on site, which is an important factor that substantially impacts time and cost of construction projects.

Considering material management, it can be noticed that material tracking and process optimization happen at various levels covering production, warehousing, and delivery process, but stop when materials arrive to construction sites considering that materials have reached their final destination (Donyavi and Flanagan 2009). Arbulu et al. (2003) for instance studied the implementation of a supplier Kanban system from suppliers to the construction site. However, looking through the eyes of crews on site, material arrival to site does not mean that the materials are in the right place. Crews still need to transport materials to the workplaces where they are installed/used. Then many questions arise, how materials will be replenished from storage locations on site to workplaces? How do the replenishing methods affect labor productivity? What if crews had to get materials from other workplaces? How do the materials for a certain crew at the workplace affect other crews' performance?

All of these questions still need to be answered. Some studies tackled similar issues through considering site material management principles and effective site layout on typical construction sites to reduce logistics costs and time delays (Harmanani et al. ; Said and El-Rayes 2013; Akinci et al. 2002). Other researches considered effective handling of materials on site which reduces waste and increases labor productivity, yet the way this issue is addressed was through material storage techniques and not through on-site material logistics (be it push or just-in-time) from storage places to workplaces. For example, many studies showed that insufficient material distribution methods, extensive multiple handling of material, improper material sorting (mismatching materials to locations), material shortage, and trash obstructing access are factors that reduce labor productivity on construction sites (Tommelein 1998a; Thomas, Sanvido and Sanders 1989a; Thomas et al. 2005; Singh 2010; El-Gohary and Aziz 2013).

Moreover, Seppänenand Peltokorpi (2016) studied the effect of on-site logistics on labor productivity through reviewing what factors (and factor's interconnections) were linked to productivity. The authors found out that the direct impact of storage locations 
on labor productivity due to skilled labor moving material was not clearly covered in the literature (Seppänen and Peltokorpi 2016).

Moving to production planning and control, it is traditionally defined as a management practice used to reduce variations from schedules and budgets; it tries to manage schedules reactively. To better manage production in construction industry, lean construction principles are applied, whereby value in the eyes of the customer is maximized, waste is reduced, constraints are removed, and workflow becomes more reliable (Howell and Ballard 1998; Hamzeh et al. 2015).

Traditional planning and controlling approaches are mainly applied push-driven techniques. Construction projects are planned by forming the activities along with their relations, resources and durations, and then schedules calculate the start and finish dates based on the critical path method (CPM)(Kelley Jr and Walker 1959). Project control then tries to stick to the planned schedule during execution assuming that all resources needed to start an activity will be available once an activity start date is reached. Thus once the activity is released after its predecessor is done, it waits passively until all the required constraints are removed. Constraints include the availability of material, information, labor, equipment and space. In case of the availability of some ingredients and the lack of others, those available ones have to wait in a queue, or the activity may start with partial requirements, also called making-do (Koskela 2004), with high probability of losing expected productivity (Tommelein 1998b; Thomas, Sanvido and Sanders 1989b; Howell et al. 1993).

Although some schedules account for uncertainties that could arise during execution such as uncertainty in duration and dependency logic, dealing with these uncertainties during real time execution should not be through trying to adhere to the planned schedule. This is because the actual network conditions and resource availability may differ from those assumed during planning (Tommelein 1998b). Thus the traditional push approach used in schedules, and the way of controlling production during execution with no appropriate rescheduling affect project performance negatively.

An alternative approach for production planning and control is the pull system. This system allows the end user to pull value from the producer (Koskela 2004). It is a demand driven system that only allows information and material to pass to a system only if the system is capable of handling them (Ballard 2000). Unlike a push system that forces the implementation of the schedule, pull systems prioritize the release of work based on the actual state of the system (Hopp and Spearman 1996).

Last Planner System (LPS) is considered a pull controlling system, as it ensures that all constraints are removed before allowing an activity to start (Ballard and Howell 1998). Location Based Management System (LBMS) also applies lean theories through aiming at reducing waste, decreasing variability, and increasing productivity. It can be applied in a pull fashion by accepting additional crews on site only when locations are available (Seppänen 2009). Moreover, the combination of both systems (LPS and LBMS) can lead to better project performance (Seppänen et al. 2010).

Although the concepts of push and pull systems are clearly defined, their practical implementations in construction projects are still not clear enough. Thus, there is a need 
to study what it actually means to push and pull in production control and construction logistics at the level of locations within the project.

\section{THE NEED TO ADD A NEW LAYER OF PRODUCTION CONTROL AND CONSTRUCTION LOGISTICS AT THE LEVEL OF LOCATIONS}

Previous research discussed site material management, its principles, best practices for material storage on congested sites, and some techniques to reduce hauling distances and transportation costs. However, on congested sites, labor productivity becomes of primary importance. Some papers address the impacts of logistics on labor productivity (e.g. Thomas et al. 2005; Singh 2010; El-Gohary and Aziz 2013). However, they do not present clear guidance regarding onsite material logistics, be it push or just-in-time. It was noticed as well that material tracking covers all stages of supply chain including production, warehousing, and delivery process, but stops once materials reach construction sites, considering that it arrived to its final destination. Yet, from the crews' point of view, materials still need to be hauled to the workplaces, and different techniques used to procure these materials from storage areas to workplaces have different effects on crew performance and productivity. This issue has received little attention in the literature. Therefore, this research studies push and just-in-time material replenishment systems, applied to material handling between areas within a construction site.

As for production control, it was noticed that some pull techniques are studied and applied in LBMS and LPS. Moreover, the traditional push method has been compared to pull technique from scheduling and control perspectives, considering tasks and project durations. However, zooming into the level of crews and locations within the project, the effects of production planning approaches on crew productivity, crew allocation to areas, and interactions between crews on the same location are still not thoroughly covered. Crew interactions include the way a crew working in a location is affected by another crew that reaches the same location/area. Moreover, the effect of applying just-in-time delivery approach for on-site materials along with pull planning is not considered in the literature. All of these gaps bring the need to study these issues and add a new layer of production planning and construction logistics at the level of project locations.

\section{PUSH AND JUST-IN-TIMEMATERIAL REPLENISHMENT APPROACHES BETWEEN PROJECT LOCATIONS}

Different approaches used to procure materials to the workplaces have different effects on labor performance and productivity. Figure 1 demonstrates the push technique for material replenishment for workplaces, whereby materials are being replenished to areas/workplaces based on a pre-set schedule, regardless if these materials are to be used straight away by a crew or not, or even if they are replenished with the right amounts and to the exact areas. Although this schedule may meet the demand sometimes, batch amounts replenished to floors may cause partial or complete obstruction to other crews 
that have to work in the same location that these materials are placed. This may cause loss in productivity due to additional congestion caused by material.

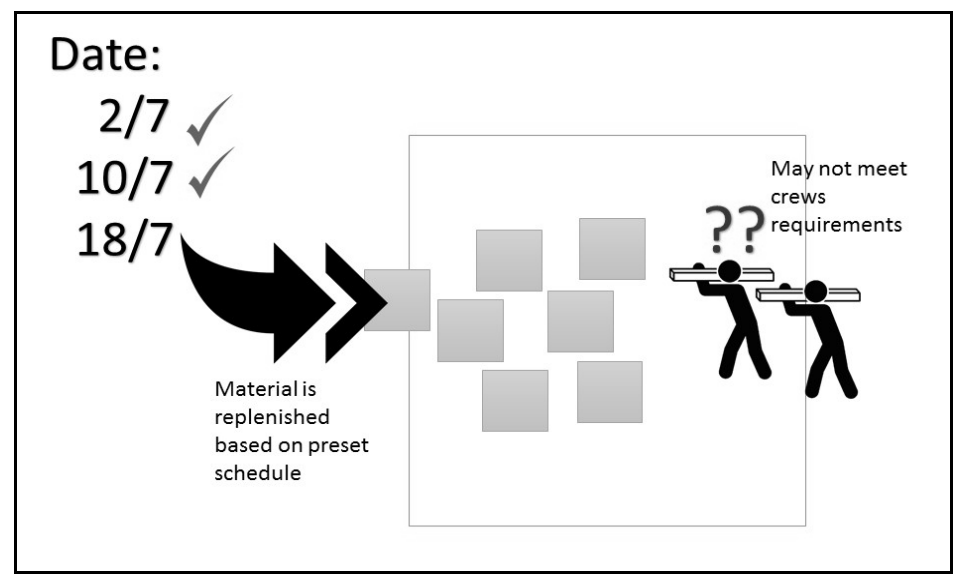

Figure 1: Demonstration of Push Technique for Onsite Material Replenishment

To better illustrate the push technique at the level of project locations, consider Figure 2 that shows how material is replenished through a push technique on a construction site, and its expected effects on crew behavior.

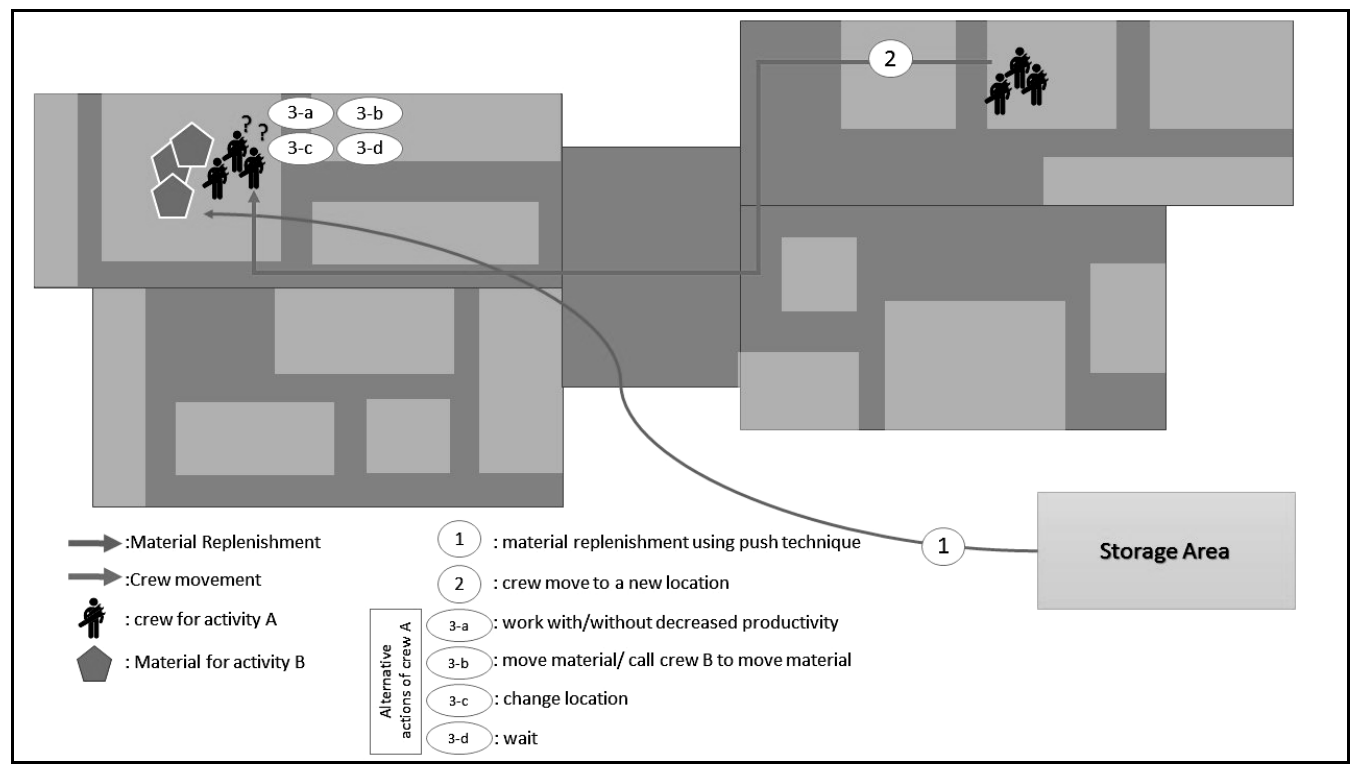

Figure 1: Effects of Push Technique for Onsite Material Replenishment on Crew Performance

According to Figure 2, materials for activity " $B$ " are being replenished from the storage area to the location shown based on a preset schedule and not on the actual demand of crews. In this case, crews for activity " $\mathrm{A}$ ", heading to work in the same location where these materials are now placed, may find some issues and thus face one of the following conditions: 
- Work with/without decreased productivity: Workers' productivity may decrease depending on the level of obstruction caused by the materials. For example, if materials are placed in the middle of a room and crews are working at the periphery of the same room, materials may cause partial obstruction to crews and thus they may work with decreased productivity.

- Move the materials/ call for crew B to move their materials: In case the crew cannot work in the presence of these materials, the crew may move the materials or call other crews responsible for moving them. For example, material " $\mathrm{B}$ " is placed in the middle of a room and crew " $\mathrm{A}$ " needs to work also in the middle. Hauling materials depends on their size and ease of handling.

- Move to another location: In case the materials cause complete obstruction and cannot be moved.

- Wait: Crew may wait for a superior decision regarding this situation, or wait if they noticed that they could start working in this location within a short time.

Notice that in almost all of the above situations, productivity is being negatively affected either due to partial material obstruction (condition 1), or due to wasting time in moving others' materials, or waiting for them to be removed (conditions 2 and 4), or even due to losing time to choose another appropriate workplaces (condition 3).

With a just-in-time technique for on-site material replenishment demonstrated in the Figure 3, productivity may be preserved in a better way. Figure 3 shows that materials are being replenished to areas based on actual demand of the corresponding crews. This way, materials are being replenished with the right amount, to the right location, and at the right time, so they do not cause obstruction and productivity loss.

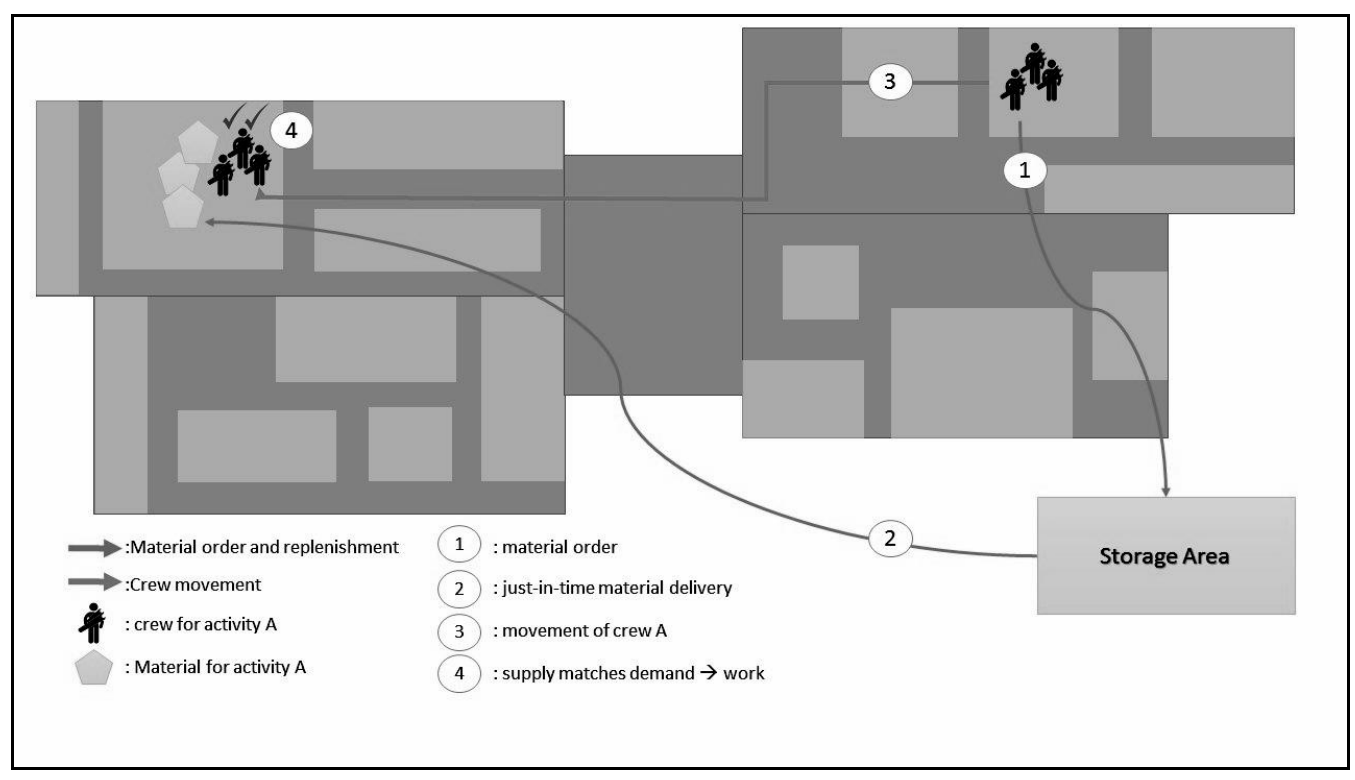

Figure 3: Just-in-time Material Replenishment at the Level of Project Locations 


\section{PUSH AND PULL TECHNIQUES FOR PRODUCTION CONTROL AT THE LEVEL OF LOCATIONS:}

Push technique at the level of locations means forcing the implementation of the schedule through assigning crews to activities as per the plan, paying less attention to their anticipated productivity. This technique is demonstrated in Figure 4 that shows crew logistics between areas following a push system.

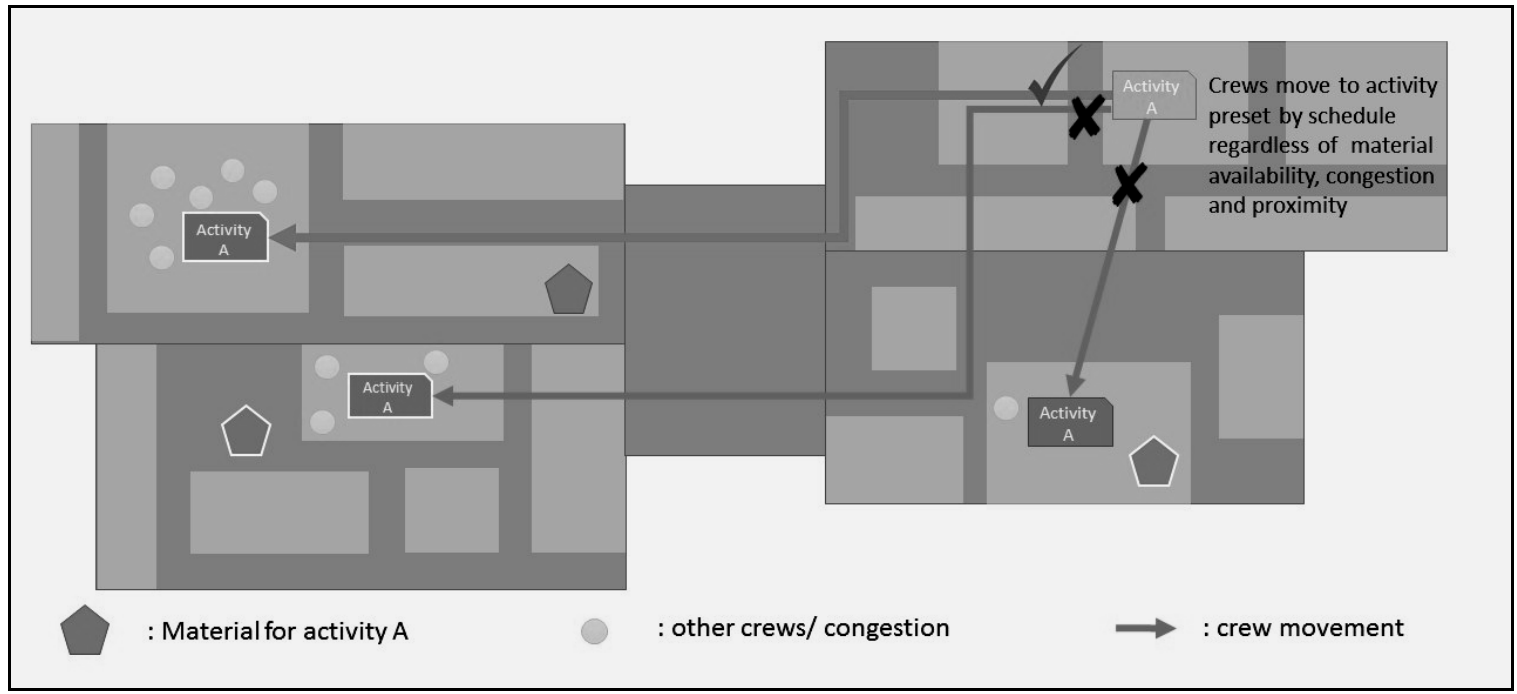

Figure 4: Crew Logistics between Areas Following Push Technique in Production Control

As shown in Figure 4, when the crew finishes activity " $A$ " in a location and needs to perform the same activity in another location, based on a push system, the crew is typically moved to the activity/location that is pre-set by the schedule, which may not account for material availability, material hauling distance, congestion caused by other crews in the location, proximity between locations, and other factors.

In this specific example, it happens that the crew moves to a location that:

- Is relatively more congested than other available areas.

- Requires material hauling over a larger distance compared to that in other areas.

- Is relatively farther than other available locations.

Now consider a pull technique that is applied for the same scenario. This is demonstrated in Figure 5, whereby all of these three alternatives are assessed taking into consideration the schedule, material availability, and anticipated production rate or congestion in the available locations. The main purpose of evaluating these alternatives is to choose the location that allows for higher labor productivity through pulling from milestones (schedule) and from the state of the system (actual conditions of congestion, material availability, etc.). 


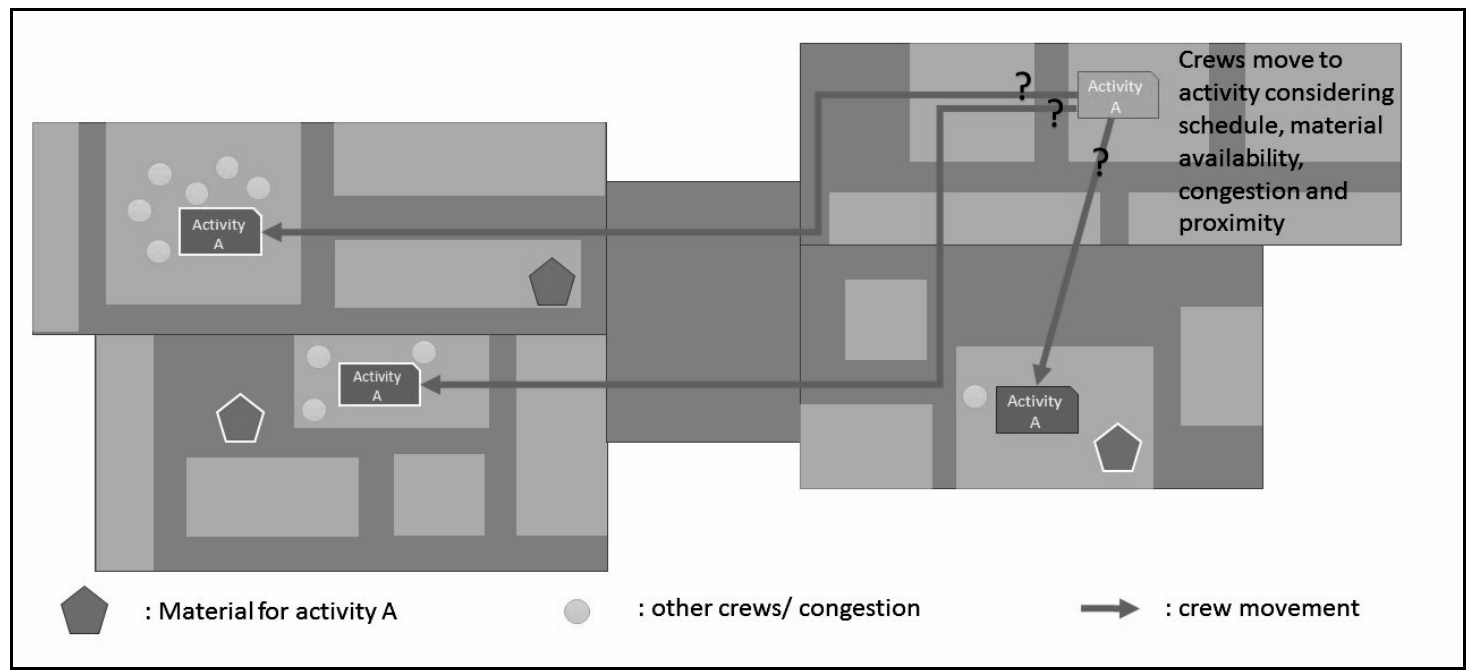

Figure 5: Crew Logistics between Areas Following Pull Technique in Production Control

Another implementation of push technique is when subcontractors work out-ofsequence or in parallel locations leaving unfinished work, without active management from the general contractor. Moreover, subcontractors tend to handle late activities through allocating more crews to a late activity in order to increase its production rate (Seppänen 2012). Push techniques can thus increase production rates when tasks are delayed but they can cause over manning and thus may lead to a loss in productivity(Thomas 1992; Singh 2003). This shows the need to use pull techniques in production control that are expected to help in increasing labor productivity and production rate at the same time.

Therefore, future research should test and compare the effects of push and pull in production control, at the level of locations, on crew performance, and test the following propositions:

1. Over manning can be counterproductive if adopted to finish a late project on time.

2. Pull can increase productivity and production rate unlike push that only increases production rate sacrificing productivity.

3. Pull achieves shorter cycle times and decreases cost.

4. Pull in production planning should be accompanied by pull in production control to be efficient (not pushing the pull schedule during execution).

Moreover, future research should test and compare the effects of push and just-in-time techniques, at the level of locations, on crew performance.

\section{CONCLUSION}

Extensive research is performed on many aspects of construction logistics, including research on site material management and delivery approaches to construction sites. Far less attention has been put onto construction logistics of crews and materials between areas within a construction site. Applying a push technique for material replenishment to workplaces shows negative effects on labor productivity. This can be avoided through 
applying just-in-time material logistics between locations. As for production control, it was shown that push and pull are compared based on their effects on tasks and general project performance without going deep into the level of crew logistics between areas within a project. This paper added this missing layer through showing how a push method reduces crew productivity despite increasing production rate, and hypothesizing that applying pull systems increases both productivity and production rate.

Future research should test the effects of push and pull applied in construction logistics and production control on labor performance, and address the propositions through isolating factors identified in this paper and testing the effect of each on productivity.

This research is valuable for researchers and practitioners seeking improvements in productivity due to exposing important applications in construction logistics and production control that affect labor productivity.

\section{REFERENCES}

Akinci, B., Fischer, M., and Kunz, J. (2002). "Automated Generation of Work Spaces Required by Construction Activities." J.Constr.Eng.Manage., 128(4), 306-315.

Arbulu, R., Ballard, G., and Harper, N. (2003). "Kanban in construction." Proceedings of IGLC-11, Virginia Tech, Blacksburgh, Virginia, USA, 16-17.

Ballard, G., and Howell, G. (1998). "Shielding Production: Essential Step in Production Control." J.Constr.Eng.Manage., 124(1), 11-17.

Ballard, G. H. (2000). "The Last Planner System of Production Control". University of Birmingham.

Donyavi, S., and Flanagan, R. (2009). "The impact of effective material management on construction site performance for small and medium sized construction enterprises." Proceedings of the 25th Annual ARCOM Conference, Nottingham, UK, 11-20.

El-Gohary, K. M., and Aziz, R. F. (2013). "Factors influencing construction labor productivity in Egypt." J.Manage.Eng., 30(1), 1-9.

Guffond, J., and Leconte, G. (2000). "Developing construction logistics management: the French experience." Constr.Manage.Econ., 18(6), 679-687.

Hamzeh, F. R., Tommelein, I. D., Ballard, G., and Kaminsky, P. (2007). "Logistics centers to support project-based production in the construction industry." Proceedings of the 15th Annual Conference of the International Group for Lean Construction (IGLC 15), 181-191.

Hamzeh, F. R., Zankoul, E., and Rouhana, C. (2015). "How can 'tasks made ready' during lookahead planning impact reliable workflow and project duration?" Constr.Manage.Econ., 33(4), 243-258.

Harmanani, H., Zouein, P., and Hajar, A. "An Evolutionary Algorithm for Solving the Geometrically Constrained Site Layout Problem." Computing in Civil and Building Engineering (2000), American Society of Civil Engineers, 1442-1449.

Hopp, W. J., and Spearman, M. L. (1996). "Factory Physics: Foundations of Manufacturing Management, Richard D." Irwin, Chicago, IL.

Howell, G., and Ballard, G. (1998). "Implementing lean construction: understanding and action." Proc. 6 th Ann. Conf. Intl. Group for Lean Constr. 
Howell, G., Laufer, A., and Ballard, G. (1993). "Interaction between subcycles: One key to improved methods." J.Constr.Eng.Manage., 119(4), 714-728.

Kelley Jr, J. E., and Walker, M. R. (1959). "Critical-path planning and scheduling." Papers presented at the December 1-3, 1959, eastern joint IRE-AIEE-ACM computer conference, ACM, 160-173.

Koskela, L. J. (2004). "Moving on-beyond lean thinking." Lean Construction Journal, 1(1), 24-37.

Koskela, L. (2004). "Making-do-The eighth category of waste."

Said, H., and El-Rayes, K. (2013). "Optimal utilization of interior building spaces for material procurement and storage in congested construction sites." Automation in Construction, 31 292-306.

Seppänen, O. (2012). "A production control game for teaching of location-based management system's controlling methods." International Group for Lean Construction.

Seppänen, O. (2009). "Empirical research on the success of production control in building construction projects." A PhD Thesis, Department of Structural Engineering and Building Technology, Helsinki University of Technology, Finland.

Seppänen, O., Ballard, G., and Pesonen, S. (2010). "The combination of last planner system and location-based management system." Lean Construction Journal, 6(1), 43-54.

Seppänen, O., and Peltokorpi, A. (2016). "A New Model for Construction Material Logistics: From Local Optimization of Logistics Towards Global Optimization of OnSite Production System." 24th Annual Conference of the International Group for Lean Construction.

Singh, A. (2003). "Accelerated work-schedule design considering efficiency losses for overtime and overmanning." Engineering, Construction and Architectural Management, 10(5), 312-321.

Singh, S. P. (2010). "Factors affecting the productivity of construction operations in the United Arab Emirates". Heriot-Watt University (United Kingdom).

Thomas, H. R. (1992). "Effects of Scheduled Overtime on Labor Productivity." J.Constr.Eng.Manage., 118(1), 60-76.

Thomas, H. R., Sanvido, V. E., and Sanders, S. R. (1989a). "Impact of material management on productivity-A case study." J.Constr.Eng.Manage., 115(3), 370-384.

Thomas, H. R., Sanvido, V. E., and Sanders, S. R. (1989b). "Impact of material management on productivity-A case study." J.Constr.Eng.Manage., 115(3), 370-384.

Thomas, R. H., Riley, D. R., and Messner, J. I. (2005). "Fundamental Principles of Site Material Management." J.Constr.Eng.Manage., 131(7), 808-815.

Tommelein, I. D. (1998a). "Pull-driven scheduling for pipe-spool installation: Simulation of lean construction technique." J.Constr.Eng.Manage., 124(4), 279-288.

Tommelein, I. D. (1998b). "Pull-driven scheduling for pipe-spool installation: Simulation of lean construction technique." J.Constr.Eng.Manage., 124(4), 279-288. 